'Fundação Oswaldo Cruz (Fiocruz), Centro de Pesquisas René Rachou (CPaRR) - Belo Horizonte (MG), Brasil.Universidade de Coimbra - Portugal. helenacampos@cpqr. fiocruz.br

2 Fundação Oswaldo Cruz (Fiocruz), Centro de Pesquisas René Rachou (CPqRR) - Belo Horizonte (MG), Brasil.

claudiagap@cpqrr.fiocruz.br

${ }^{3}$ Fundação Oswaldo Cruz (Fiocruz), Centro de Pesquisas René Rachou (CPqRR) - Belo Horizonte (MG), Brasil.

isabellacaraujo@hotmail.

com

4 Pontifícia Universidade Católica de Minas

Gerais (PUC-MG) - Belo

Horizonte (MG), Brasil.

yagoferreiraf@gmail.com

${ }^{5}$ Universidade Federal de Minas Gerais (UFMG), Centro de

Desenvolvimento e

Planejamento Regional

(Cedeplar) - Belo

Horizonte (MG), Brasil.

fonseca.mc@uol.com.br

\section{Direitos humanos, cidadania sexual e promoção de saúde: diálogos de saberes entre pesquisadores e adolescentes}

\author{
Human rights, sexual citizenship and health promotion: dialogues of \\ knowledge between researchers and adolescents
}

Helena Maria Campos', Cláudia Gersen Alvarenga Paiva², Isabella Campos de Araújo Mourthé3, Yago Freire Ferreira $\mathbf{4}^{\text {, Maria do Carmo Fonseca }} \mathbf{5}$

RESUMO Este artigo apresenta uma experiência de educação em saúde conduzida por pesquisadores e estudantes do Ensino Médio de uma escola pública de Belo Horizonte (MG). Demonstra como problematizar direitos humanos, saúde e cidadania sexual, contextualizada à realidade de adolescentes. Evidenciou-se que a precariedade da vida, iniquidades de gênero, silenciamentos, negação de direitos sexuais, informações qualificadas insuficientes afetam a saúde sexual de adolescentes. O diálogo de saberes entre pesquisadores e adolescentes sobre direitos sexuais interfere positivamente na promoção da saúde sexual. Este relato pode contribuir para o planejamento de atividades na atenção primária para a promoção de saúde.

PALAVRAS-CHAVE Direitos humanos. Direitos sexuais e reprodutivos. Educação em saúde. Saúde sexual. Adolescente.

ABSTRACT This article presents an experience of health education conducted by researchers and High School students of a public school in Belo Horizonte (MG). It demonstrates how to problematize human rights, health and sexual citizenship, contextualized to the reality of adolescents. It has been emphasized that precariousness of life, gender inequities, silencing, denial of sexual rights, insufficient qualified information affect the sexual health of adolescents. The dialogue of knowledge between researchers and adolescents about sexual rights interferes positively in the promotion of sexual health. This report may contribute to the planning of activities in primary attention, for health promotion.

KEYWORDS Human rights. Sexual and reproductive rights. Health education. Sexual health. Adolescent. 


\section{Introdução}

A adolescência é uma fase da vida marcada por transformações físicas, psicológicas e sociais, singularizadas pelos contextos social, histórico e cultural, sendo, portanto, muitas as formas de vivenciar esta etapa. Desta maneira, é mais adequada a utilização do termo adolescências.

Ozella e Aguiar (2008) consideram que as concepções do termo 'adolescência', comumente difundido como um período de crise, cumprem o papel ideológico de camuflar a realidade, as contradições sociais, as verdadeiras mediações que constituem tal fenômeno. A partir deste prisma, a sociedade destaca marcas da adolescência como se fossem universais e naturais, entretanto, cada adolescente é singular, tem sua própria história, sua forma de ser e estar no mundo.

A sexualidade humana também é uma construção social e cultural, que, nas especificidades da adolescência, é marcada por descobertas e experimentações, crescente autonomia e tomadas de decisões, o que torna fundamental propiciar educação sexual e informações qualificadas aos adolescentes. A sexualidade é uma energia que motiva a procura pelo amor e pela intimidade, e integra-se ao modo de cada pessoa sentir e experimentar emoções, relações, ações e interações, por isso, influencia a saúde física e mental (PAHO; WHO, 2000).

Diante disso, tem-se proposto promover a saúde sexual, que é definida como relações sexuais saudáveis, protegidas de Infecções Sexualmente Transmissíveis (ISTs), livres de coerção, discriminação e violência (CORRÊA; ALVES; JANUZZI, 2006), por meio de abordagens participativas, que favoreçam o conhecimento de si e do outro, através de diálogos críticos e reflexivos. Corrêa, Alves e Januzzi (2006, P. 53) ressaltam que, "para se alcançar e manter a saúde sexual, os direitos sexuais de todas as pessoas devem ser respeitados, protegidos e satisfeitos".

Os direitos sexuais de adolescentes são indicados como direitos fundamentais à vida em diversos documentos e reafirmados pelo Ministério da Saúde (BRASIL, 2009), que os conceitua como: 1) Direito de viver e expressar livremente a sexualidade sem violência, discriminações e imposições, e com respeito pleno pelo corpo do(a) parceiro(a); 2) Direito de escolher o(a) parceiro(a) sexual; 3) Direito de viver plenamente a sexualidade sem medo, vergonha, culpa e falsas crenças; 4) Direito de viver a sexualidade independentemente de estado civil, idade ou condição física; 5) Direito de escolher se quer ou não quer ter relação sexual; 6) Direito de expressar livremente sua orientação sexual: heterossexualidade, homossexualidade, bissexualidade, entre outras; 7) Direito de ter relação sexual independente da reprodução; 8) Direito ao sexo seguro para prevenção da gravidez indesejada e de Doenças Sexualmente Transmissíveis (DSTs); 9) Direito a serviços de saúde que garantam privacidade, sigilo e atendimento de qualidade e sem discriminação; 10) Direito à informação e à educação sexual e reprodutiva.

Os direitos sexuais são construções relativamente recentes, frutos de reflexões teóricas e lutas políticas emancipatórias, que conquistaram o reconhecimento destes como direitos humanos, dimensionados a partir de valores democráticos. $\mathrm{O}$ reconhecimento, o amplo conhecimento e o acesso aos direitos sexuais de adolescentes são fundamentais para promover a saúde sexual e propiciar o exercício da cidadania sexual. A educação em sexualidade é um desses direitos sexuais, portanto, é considerada fundamental para esse grupo populacional (HEILBORN, 2012).

A educação em sexualidade, introduzida como educação em saúde no campo da sexualidade, pautada no modelo dialógico, possibilita a transformação dos saberes e propicia ampliação de conhecimentos, especialmente sobre direitos sexuais (CAMPOS; ARAÚJO; SCHALL, 2011; CAMPOS; SCHALL; NOGUEIRA, 2013).

Alguns dos fatores associados à saúde sexual de adolescentes têm sido apontados 
como problemas de saúde pública, reconhecidos pela Organização Mundial da Saúde (OMS) e objetos de reflexão de diversos estudos. Entre estes fatores, destacam-se: a iniciação sexual desprotegida; o reduzido uso de preservativos em todas as relações sexuais; o baixo uso de métodos de proteção; Infecções Sexualmente Transmissíveis/Síndrome da Imunodeficiência Adquirida (ISTs/Aids); iniquidades de gênero; violência; gravidez na adolescência; e outros agravos à saúde, que geralmente geram efeitos nos percursos escolares (TEIXEIRA ET AL., 2006; HEILBORN, 2006; CAMPOS; SCHALL; NOGUEIRA, 2013; IBGE, 2016).

A educação em saúde tem sido indicada na atenção primária para promover saúde. Hoje a saúde é estudada sob vários pontos de vista devido à complexidade e aos multifacetados fatores que afetam as dimensões da vida e da morte. A educação em saúde emancipatória afinada à realidade dos adolescentes se constitui como estratégia promissora para promover a saúde sexual, sobretudo na perspectiva da justiça cognitiva (SANTOS, 2007) e da educação participativa e transformadora (FREIRE, 1996), sendo almejada por profissionais da saúde e da educação.

Para os setores saúde e educação, o conceito de justiça cognitiva, teorizado por Boaventura de Sousa Santos, tem potencial para favorecer a produção de conhecimento por e com os envolvidos no processo saúde-doença e no processo ensino-aprendizagem. A justiça cognitiva é a proposta de participação dos sujeitos na apropriação, concepção e produção de conhecimentos (SANTOS, 2007).

Campos, Schall e Nogueira (2013) ressaltam que, na promoção da saúde de adolescentes, é importante envolvê-los em todas as etapas do processo de construção de conhecimentos, considerar aspectos cognitivos e afetivos, propiciar espaços de diálogos criativos e reflexões críticas. Para Schall (2005), a educação em saúde deve permitir a construção do saber comprometido com o desenvolvimento de valores afinados com a autoestima, o respeito a si e aos outros, e a responsabilidade social, contextualizado ao meio sociocultural onde os adolescentes vivem.

Uma educação em saúde em sintonia com a realidade dos sujeitos e com a justiça cognitiva poderá promover saúde e gerar transformações individuais e coletivas. Neste sentido, este artigo apresenta uma experiência de diálogos de saberes sobre direitos humanos, saúde e cidadania sexual entre pesquisadores e um grupo de adolescentes.

\section{Contexto da experiência}

Esta experiência foi desenvolvida no âmbito do Doutorado em Saúde Coletiva, no Centro de Pesquisas René Rachou (CPqRR), da Fundação Oswaldo Cruz (Fiocruz), em cotutela com o Programa em Direitos Humanos nas Sociedades Contemporâneas, da Universidade de Coimbra, Portugal. Faz parte de uma pesquisa qualitativa realizada com adolescentes, alunos do Ensino Médio de uma escola pública em Belo Horizonte (MG). Esta pesquisa foi aprovada pelo Comitê de Ética do Centro de Pesquisas René Rachou/Fiocruz sob o parecer $\mathrm{n}^{\mathrm{o}}$ 986.210, Certificado de Apresentação para Apreciação Ética no 36399214.3.0000.5091.

O que motivou a produção de conhecimento compartilhado foi a evidência de que os adolescentes que participaram da pesquisa desconheciam os direitos sexuais e não costumavam obter informações sobre sexualidade com familiares e professores, sendo os amigos e a internet suas principais fontes de informação, consideradas insuficientes por eles mesmos.

Diante dessas constatações, a equipe de pesquisa deste estudo julgou procedente realizar uma estratégia de educação em saúde com 30 adolescentes, que aceitaram o convite para participar desta pesquisa, atenderam aos critérios de inclusão e assinaram os Termos de Consentimento Livre e Esclarecido (TCLE). Os participantes têm de 14 a 18 anos de idade; 19 deles são do sexo 
feminino e 11 do sexo masculino; são alunos do $1^{\circ}$, do $2^{\circ}$ e do $3^{\circ}$ ano do Ensino Médio da escola pública selecionada; advêm de famílias de baixa renda, com multiplicidade de configurações; residem em bairros da periferia da cidade. Realizou-se uma oficina com a finalidade de devolver aos participantes da pesquisa os resultados do estudo e propiciar espaço de diálogos sobre suas dúvidas, além de informações qualificadas sobre direitos sexuais e saúde sexual.

A oficina, conceituada como

um trabalho estruturado com grupos, independentemente do número de encontros, se centraliza em torno de uma questão (tema), cuja elaboração acontece em um contexto social. (AFONSO, 2000, P. 11),

possibilita a construção de conhecimentos de forma coletiva e contextualizada.

A efetividade do uso das oficinas, enquanto metodologia de intervenção aplicada ao contexto da saúde coletiva, vem sendo reconhecida e incentivada pela literatura acadêmico-científica, particularmente com adolescentes (CAMPOS; ARAÚJO; SCHALL, 2011), podendo ser aplicada em diversas áreas do conhecimento (PRESOT; CAMPOS; MODENA, 2013; ALBUQUERQUE ET AL., 2014).

No planejamento da oficina, definiram-se o tema, as técnicas grupais e, as atividades educativas, reflexivas e avaliativas que seriam utilizadas para alcançar os objetivos. Além disso, distribuíram-se as responsabilidades entre os membros da equipe de pesquisa.

No enquadre, realizou-se um levantamento do tempo, espaço e recursos necessários. Foi escolhida uma sala ampla, na própria escola, com cadeiras móveis para formar círculo, propiciando interação face a face, relações horizontais, escuta atenta, valorização da fala de cada um e do potencial de todos (CAMPOS; ARAÚJO; SCHALL, 2011).

O grupo de pesquisadores participou do processo educativo como mediador e 'copensador’, com a função de provocar reflexão, trazer a dúvida, problematizar o que está naturalizado, motivar o grupo a pensar, encontrar suas respostas e construir o próprio conhecimento (ANDALÓ, 2001).

A oficina teve a duração de duas horas e foi gravada com o consentimento dos participantes. Posteriormente, foi transcrita, realizada análise de conteúdo e interpretação das informações em profundidade. Houve, também, registro de observações em diário de campo.

\section{A experiência: oficina em direitos sexuais}

Na estrutura dessa oficina, foram consideradas dimensões cognitivas, afetivas e psicossociais, com as seguintes etapas:

1. Acolhimento: disposição para receber todas as manifestações dentro de determinado tempo e tema. A oficina iniciou com o acolhimento, momento em que a equipe de pesquisadores recebeu os estudantes na porta da sala com boas-vindas, direcionando-os a se sentarem em círculo, para valorizar a participação de todos e a troca de experiências e saberes. Isto fundamentado na proposta pedagógica de Paulo Freire (1987, P. 39), que ressalta:

Já agora ninguém educa ninguém, como tampouco ninguém se educa a si mesmo: os homens se educam em comunhão, mediatizados pelo mundo.

A construção do conhecimento se faz a partir das interações e trocas de saberes, onde ninguém detém um completo saber, aprendemos uns com os outros permanentemente. $\mathrm{O}$ processo ensino-aprendizagem é contínuo, dinâmico, complexo e mediatizado pelo mundo. Neste sentido, não há um completo saber sobre os eventos da vida, sobre a sexualidade e a saúde sexual, pois são processos dinâmicos entre a vida 
e a morte, inseridos em um determinado tempo e contexto sócio-histórico.

2. Técnica de integração: visa integrar os participantes do grupo, à constituição de vínculos, pois as relações afetivas têm uma importância vital para o desenvolvimento humano. Nessa etapa da oficina, cada participante se apresentou ao grupo, dizendo nome, série que estudava e expectativa sobre o encontro. Assim, a rede relacional foi sendo tecida, através dos olhares, dos risos, da proximidade, das falas de cada um e no entrelace das histórias de vida.

A princípio, os adolescentes estavam tímidos, desconfiados, mas, à medida que foram compreendendo a proposta educativa, sendo acolhidos e sentindo confiança, foram ampliando suas participações e expressando as próprias opiniões e sentimentos. Eles comentaram que nunca tinham vivido esse tipo de atividade sobre sexualidade na escola, e que, geralmente, não têm chances de expressarem seus pensamentos. Um adolescente reflete:

Eu acho que a gente sempre quer se expressar, mas nunca tem chance de falar. Igual esse trabaIho aqui, que a gente está fazendo: é uma oportunidade d'a gente se expressar. Às vezes, a gente quer falar alguma coisa e não tem... Aí, fala com amigo. (Participante 1).

A educação acontece através da palavra, propiciando a superação das fragmentações humanas e transformando ato em palavra, pois o ato antecede a palavra. Se os adolescentes não encontram espaços para a palavra, a tendência é se fixarem no ato, pois, sem palavra, não há diálogo, negociação e/ou consenso. Nessa experiência, evidenciou-se que não há espaços para adolescentes dialogarem sobre suas relações sexuais e esclarecerem suas dúvidas sobre métodos protetivos, o que os torna mais vulneráveis, já que acabam praticando sexo sem proteção. A família, a escola e a sociedade deveriam criar espaços privilegiados para a circulação da palavra, principalmente para a escuta da palavra dos adolescentes.

O diálogo é a oportunidade de exercer o direito à palavra, sem a qual não haveria relação humana. Nesta perspectiva, Freire (1989, P. 13) entende que as palavras são carregadas de intenções e tensões, "a leitura do mundo precede a leitura da palavra e uma não prescinde da outra"; há um movimento dinâmico entre a leitura do mundo e a palavra.

Nesse sentido, é indispensável propiciar espaços de diálogo, escutar as palavras dos adolescentes para se compreender o contexto e o mundo em que vivem. Essa é a primeira condição para o desenvolvimento de atividades educativas que façam sentido para eles. Desta maneira, a educação em sexualidade abre espaço para a escuta da palavra dos adolescentes, de suas dores e prazeres, seus medos e alegrias, suas relações afetivas e sexuais. Esta escuta, o respeito aos saberes e à autonomia dos educandos possibilita a eles uma releitura e ressignificação do mundo e, consequentemente, reflexão crítica sobre a própria vida, configurando seu direito de decidir sobre os atos que definem a sua saúde sexual.

3. Contrato de convivência: construído pelo próprio grupo em torno do qual vão girar as demais atividades e a construção grupal propriamente dita, procura manter uma convivência agradável, solidária, com respeito às diferenças. Neste contrato, elaborado pelo grupo (adolescentes e pesquisadores), definiram-se: horários de início e fim; que a participação de cada um seria com respeito; livre expressão das ideias; escuta atenta de cada um; e sigilo sobre relatos pessoais. Os adolescentes demonstraram desejo de expressar seus pensamentos e sentimentos pautados em verdade, confiança e respeito.

4. Aquecimento: para dialogar sobre direitos sexuais, cidadania sexual e promoção da saúde, realizou-se um aquecimento, a fim de desenvolver os temas, com a apresentação da música 'Não é sério’, da banda 
Charlie Brown Jr. Os participantes prestaram atenção na letra e refletiram criticamente, ressaltando, cada um, a parte que mais gostou, o que chamou a atenção e/ou o que não entendeu. Ao término da música, abriu-se um debate sobre a realidade dos jovens no Brasil. Cada um pôde expressar seus sentimentos e pensamentos, relacionando-os aos seus direitos.

Emergiu o sentido de que adolescentes 'não são levados a sério pela sociedade', pois não são considerados como sujeitos de direito, não são reconhecidos como cidadãos com direito a 'voz e nem vez’ na formulação de políticas públicas. Ademais, relataram que a visão sobre eles é sempre negativa, como se os jovens não soubessem nada e todos fossem 'rebeldes e marginais', conforme narrativas de dois adolescentes:

Ninguém nunca leva a sério as nossas opiniões, tanto os nossos pais quanto qualquer pessoa. Tudo, em qualquer assunto que estou falando, todas as nossas opiniões, todo mundo sempre ignora, pelo fato de acharem que nós somos muito inocentes, que a gente é muito jovem, que a gente não conhece as coisas... (Participante 2).

Eu sempre quis falar e nunca tive chance. Às vezes, você quer falar com seu pai o que está acontecendo com você, mostrar o que está sentindo, só que, quando você começa a falar, ele já te barra; ele fala que você é muito jovem, você não tem que viver isso, não... (Participante 3 ).

Essas narrativas afirmam a necessidade de espaços virtuosos de diálogos e, principalmente, a demanda por escuta e confiança no que é dito por eles, reconhecendo-os em sua autonomia e saberes. A restrição das falas e a desqualificação dos sentidos trazidas nas palavras dos adolescentes sinalizam violação de direitos sexuais e, por sua vez, de direitos à saúde, qualificados como direitos humanos fundamentais. Conforme afirmam Seffner e Parker (2016, P. 297),

podemos ter ações que contribuem para diminuir ou mesmo eliminar a precariedade, e ações que aumentem a precariedade da vida, tais como injúrias ao indivíduo, exposição à vergonha, à exploração do seu corpo,

humilhações, violências e outras situações precárias que roubam a vida. Estes autores se inspiram nas ideias de Judith Butler sobre a precarização da vida humana, nas quais a ênfase recai sobre a ética das relações humanas, que privilegia pensar na interdependência entre os seres humanos, em reconhecer o outro que depende de mim e de quem eu dependo. Neste sentido, a noção de precariedade implica no não reconhecimento da fragilidade da vida e da fragilidade do outro com o qual se relaciona.

Adolescentes apontaram vivências relacionadas à precariedade da vida, como maus-tratos, negligências, incompreensões, dores, violências e discriminações, que tornam a vida deles precárias, pois afetam a autoestima e a saúde. Isto pôde ser constatado nas seguintes narrativas:

Todos os jovens são colocados na mesma opinião, tipo, todos são marginais, que a maioria é marginal, e existe jovem diferente disto. (Participante 4).

Eu também sinto dor. Porque muita gente acha: 'Ah, você é jovem, você não sente nada, você tem tudo na mão; a gente te dá tudo e você não sente dor nenhuma'. (Participante 5).

[...] quando a gente é maltratada, a gente perde um pouquinho a esperança, a gente para de acreditar um pouco em si [...]. (Participante 6).

A luta por uma vida menos precária e mais digna poderia se iniciar pela desconstrução dos preconceitos em relação à própria adolescência, pelo reconhecimento dos adolescentes como sujeitos de direito, bem como pela garantia e o acesso aos seus direitos sexuais, à saúde sexual e aos direitos humanos.

5. Vivência: atividade que parte dos saberes 
prévios sobre os temas da oficina e favorece o processo de construção do conhecimento. Para compreender os saberes dos adolescentes sobre saúde, foi realizada uma 'chuva de ideias', a partir das perguntas: o que é saúde para vocês? O que é saúde sexual? O que são direitos sexuais? Quais são os direitos sexuais? Registrou-se tudo que os participantes foram expressando, em associação livre, em uma folha de papel pardo, posteriormente fixada à parede da sala.

Estudantes demonstraram incertezas e dúvidas; disseram que ficavam muito no 'achismo'; reafirmaram a necessidade de obterem informações de qualidade com pessoas de confiança. Emergiu, do diálogo, a ausência de conversas sobre a sexualidade, de um modo natural, com qualquer pessoa e em qualquer lugar, por ser este um assunto velado. Como relataram, é um assunto mais 'fechado'.

Ficou evidente que, para adolescentes, saúde sexual é usar camisinha e conhecer ISTs. Isto reflete que o tipo de informações que recebem se limita à prevenção de doenças. Os saberes dos adolescentes sobre direitos sexuais se entrelaçam com saberes sobre a saúde, reduzidos a uma dimensão do saber biomédico, o que lhes escamoteia a completude dos direitos sexuais e reprodutivos, bem como o direito de decidir sobre seus próprios corpos. A pedagogia do medo, muitas vezes utilizada para evitar a gravidez, desconsidera diferentes formas de pensar, sentir e agir, e faz o foco recair sempre na gravidez vista como reclusão e impedimento de viver, conforme se vê nas seguintes narrativas:

As pessoas ficam falando que é contra o aborto. Não estou generalizando, mas normalmente são os meninos que viram para as meninas, quando elas estão grávidas, e falam 'vai fazer o aborto', ou, muitas vezes, os pais mesmo. A mãe pega a filha, que está grávida, e leva para a clínica, para ela tirar. Tipo, já aconteceu lá perto de casa, d'a menina engravidar mais de três vezes e a mãe dela levar para tirar. (Participante 7).
Porque todo mundo fala que, se na juventude você tiver um filho, você vai estragar a sua vida; que você não vai poder sair, não vai poder fazer isto... Mas tem muitas vezes que a pessoa não gosta de sair, curtir. (Participante 8).

Adolescentes fizeram críticas ao machismo, aos preconceitos e às desigualdades sexuais, conforme narrativa a seguir:

Eu acho que, para a mulher, é mais complicado falar sobre este assunto, por causa da sociedade machista. Mulher não pode gostar de sexo, só homem que pode (risos). Se a mulher gostar do trem, ela é puta; se o homem gostar, é garanhão. (Participante 9).

Eles demarcaram a necessidade de mais igualdade entre homens e mulheres, com liberdade de concepção da vida para ambos e direito à experiência livre de preconceitos.

As narrativas dos adolescentes apontam que são necessárias ações que permitam desconstruir binômios como prazer/dor, presente/passado, reprodução/sexualidade, heterossexualidade/homossexualidade. O binarismo é um sistema excludente, desigual, impositivo, com hegemonia do sexo masculino, subordinação das mulheres, construído através de um longo processo de socialização, que envolve vários agentes como a família, a escola e a sociedade.

Esses binômios abarcam um conhecimento dicotômico, reducionista; parecem simétricos, mas escondem diferenças e hierarquias, são desperdícios de experiência, porque deixam muitas realidades de fora da totalidade (SANTOS, 2007). Uma educação em sexualidade emancipatória pode propiciar conhecimento sobre o próprio corpo, sobre os eventos da vida, problematizar e desconstruir esses binômios. O silenciamento, a opressão e o desconhecimento geram mais vulnerabilidades aos adolescentes, além da persistência de preconceitos e iniquidades.

A construção de um conhecimento emancipatório, o enfrentamento das 
desigualdades entre homens e mulheres, e a equidade de gênero, bem como o reconhecimento da diversidade sexual, o respeito às diferenças e as relações amorosas e igualitárias são caminhos a serem trilhados para se alcançar saúde sexual e qualidade de vida, visto que hoje saúde é um conceito amplo, que ultrapassa ações meramente preventivas e biomédicas, devido à complexidade e aos multifacetados fatores que afetam as dimensões da vida e da morte.

6. Ampliação de informações: a interação entre pesquisadores e adolescentes ocorreu durante todo o processo dessa estratégia de educação em saúde. Nesta etapa específica da oficina, os pesquisadores apresentaram conhecimentos científicos sobre direitos sexuais, na perspectiva da justiça cognitiva, que considera os saberes populares sem desconsiderar os conhecimentos científicos. Essa atividade foi feita de forma criativa para despertar o interesse e o prazer de aprender. Foram preparadas tiras de papel, nas quais estavam impressos os direitos sexuais, e essas tiras foram inseridas em uma caixa fechada. Ao som de uma música, a caixa foi passada de mão em mão, entre os participantes da atividade. Sempre que a música era interrompida, quem estava com a caixa tirava, de dentro dela, um direito, lia o conteúdo e o explicava para os demais participantes da roda. Todos podiam dizer o que pensavam a respeito, complementar, refutar, discordar, enquanto a pesquisadora que coordenava a atividade ficava atenta para esclarecer dúvidas e complementar as informações. A caixa circulou na roda de participantes até terminar a lista dos direitos sexuais.

7. Reflexão dialógica: para facilitar a exposição dialogada, de ideias e vivências, os grupos foram divididos em subgrupos. Foram-lhes apresentadas questões instigantes sobre os temas da oficina, e propôs-se que cada subgrupo expusesse suas conclusões de forma criativa na plenária geral.
Desse modo, buscou-se garantir a justiça cognitiva através da apropriação, da concepção e da produção de conhecimentos por eles mesmos.

Os adolescentes compartilharam responsabilidades individuais e coletivas. Para sintetizar, o grupo construiu um cartaz com as seguintes palavras: "O jovem precisa ser ouvido para conseguir conquistar o seu espaço na sociedade e ser levado a sério". Além disso, eles manifestaram o desejo de transformação da realidade, e de se unirem para lutar por seus direitos e por uma vida digna, conforme a narrativa de um adolescente:

Tudo que o pessoal 'tá falando é verdade, mas, se não nos unirmos para mudar, se nós não lutarmos para mudar, conversar para tentar mudar o que está acontecendo, vai continuar a mesma coisa. (Participante 10).

Esta experiência de educação em saúde emancipatória demonstra que, abrir espaços para a escuta e a legitimação das vozes dos adolescentes, reconhecendo as suas experiências e saberes, pode gerar transformações na realidade e nas práticas de saúde. Os pesquisadores fizeram o fechamento da oficina, complementando com informações qualificadas sobre direitos sexuais e saúde sexual, e agradecendo pela participação de todos.

8. Avaliação: Tem por objetivo conseguir, dos participantes, uma avaliação do encontro nos aspectos de interação grupal, ampliação de conhecimentos, criatividade, participação e transformação. Tal avaliação pode fundamentar a alteração, a inclusão ou a subtração de atividades para a replicação desta oficina a outros grupos, ou a criação de futuras oficinas. Então, realizando-se a avaliação dessa oficina, as palavras e frases mais utilizadas por adolescentes foram:

\footnotetext{
Ah, mas já acabou?; Eu queria falar mais; Informação; Construtivo; Muito produtivo; Educacional; Escuta; Esclarecedor; Aprendi muito; Instrutivo; Gostei
} 
muito; Necessário para a gente saber os direitos que a gente tem e não sabia; Ah, podia ter isto mais aqui na escola!; Nossa, foi muito bom, porque nós sempre tivemos aula que, às vezes, tocavam nestes assuntos e nos informavam, mas nunca assim, para ouvirem o que sentimos e achamos.

Enfatizaram a relevância da escuta, da relação horizontal e do diálogo criativo entre pesquisadores e adolescentes.

Posteriormente, a equipe de pesquisa fez uma avaliação dessa experiência, analisando as falas, posturas e emoções dos participantes, inferindo que houve ampliação de conhecimentos sobre direitos sexuais, mas que há muito a se fazer para melhorar a vida dos adolescentes desse grupo. Concluiu-se que a educação em sexualidade deve ser um processo permanente e sistemático, e se estender para todos os adolescentes, conforme a narrativa de um participante: "Este tipo de atividade deveria ser para mais adolescentes". Neste sentido, a partir da limitação de se tratar de uma experiência única e singular, o tensionamento entre o singular e o coletivo abre a potencialidade para o diálogo reflexivo-crítico sobre direitos sexuais para outras experiências com grupos de adolescentes.

Concorda-se com os adolescentes sobre a necessidade de oportunizar uma educação permanente a todos, abrangendo outros temas relacionados à sexualidade, para que os sujeitos se mobilizem, lutem por seus direitos, por uma vida digna, e haja transformação da realidade. Essa experiência pode ser multiplicada tanto pelos profissionais da educação quanto da saúde, a fim de orientar novas práticas educativas em espaços formais e informais e inspirar a criação de outras oficinas, com outros temas e finalidades.

\section{Considerações finais}

A originalidade desta experiência incide em demonstrar que problematizar os direitos humanos, a cidadania sexual e a promoção da saúde, contextualizada à realidade de adolescentes, é efetiva para mobilizar os sujeitos na construção da sua saúde sexual. Os direitos sexuais, bem como os direitos humanos, só serão garantidos na medida em que adolescentes sejam reconhecidos e se reconheçam como portadores de saberes e direitos.

Essa oficina se constituiu como uma intervenção psicossocial ao abarcar dimensões pedagógicas, psicológicas e sociais, mostrando-se com potencial para promover a saúde de adolescentes. A estratégia de educação em sexualidade emancipatória demonstrou ser bastante profícua para a transformação dos indivíduos, a partir do grupo, ao abrir espaços de escuta, e contemplar aspectos cognitivos e emocionais, conscientes e inconscientes, facilitando diálogos francos sobre a própria vida, incentivando a participação de todos e a autonomia de cada um.

Nessa experiência, evidenciou-se que os direitos humanos não se efetivaram para os adolescentes, que enfrentam a precariedade da vida, as iniquidades de gênero, os silenciamentos, a negação de direitos sexuais e informações qualificadas insuficientes, que afetam a saúde sexual. Além disso, observou-se o grande potencial criativo e solidário de adolescentes, a capacidade de participação, reflexão crítica sobre a vida afetiva, construção e produção de conhecimentos.

O diálogo de saberes entre pesquisadores e adolescentes sobre direitos sexuais pode interferir positivamente na promoção da saúde sexual e, consequentemente, ser uma maneira de garantir direitos humanos, que, de outra forma, permaneceriam silenciados e invisíveis. Como sublinham contributos teóricos sobre direitos humanos e sexualidade, o silêncio pode ser violência e a invisibilidade pode gerar exclusão (SANTOS, 2005; RODRIGUES; NOGUEIRA; OLIVEIRA, 2010; SANTOS, 2012).

Sobretudo, essa experiência permitiu conhecer as peculiaridades e necessidades dos adolescentes, o que poderá contribuir para o planejamento de políticas públicas 
significativas, promoção da saúde e maior qualidade de vida a esse grupo específico.

Apesar de pontual, essa experiência proporcionou acesso aos conhecimentos e às práticas dos adolescentes, em matéria de direitos e saúde sexual. Foi possível estabelecer relações horizontais e diálogo de saberes entre adolescentes e pesquisadores, mesmo tendo assimetrias de poder e saber, marcadas pela diferença de idade, de acesso ao conhecimento e de classe social, entre outras.

A oficina constituiu-se como uma estratégia educativa emancipatória aliada à justiça cognitiva ao considerar não só os conhecimentos científicos, mas também os saberes de adolescentes, ampliando a compreensão dos fenômenos e potencializando ações coletivas de luta por direitos, por mais qualidade de vida e pela garantia das condições materiais e imateriais necessárias a uma existência digna.

\section{Colaboradores}

Helena Maria Campos contribuiu com a concepção, o planejamento, a análise e a interpretação de dados, a revisão crítica e a aprovação da versão final do manuscrito. Cláudia Gersen Alvarenga de Paiva contribuiu com a análise dos dados, a revisão crítica e a aprovação final do manuscrito. Isabella Campos de Araújo Mourthé contribuiu com a transcrição da oficina, a análise dos dados, a revisão crítica e a aprovação final do manuscrito. Yago Freire Ferreira contribuiu com a análise e a interpretação dos dados, a revisão crítica e a aprovação final do manuscrito. Maria do Carmo Fonseca contribuiu com a orientação, a revisão crítica do conteúdo e a aprovação final do manuscrito.

Ressalte-se que este manuscrito é original, inédito e não foi publicado em outra revista.

\section{Agradecimentos}

Os autores agradecem ao Centro de Pesquisa René Rachou/Fiocruz e à Secretaria de Estado de Educação de Minas Gerais pelo apoio institucional e incentivo à realização deste estudo, bem como às escolas e aos participantes da pesquisa. 


\section{Referências}

AFONSO, L. Oficinas em Dinâmica de grupo: um método de intervenção psicossocial. Belo Horizonte: Campo Social, 2000.

ALBUQUERQUE, O. M. R. et al. Percepção de estudantes de escolas públicas sobre o ambiente e a alimentação disponível na escola: uma abordagem emancipatória. Saúde e Sociedade, São Paulo, v. 23, n. 2, p. 604-615, 2014

ANDALÓ, C. S. A. O papel do coordenador de grupos. Psicologia USP, São Paulo, v. 12, n. 1, p. 135-152, 2001.

BRASIL. Ministério da Saúde. Direitos sexuais, direitos reprodutivos e métodos anticoncepcionais. Brasília, DF: Ministério da Saúde, 2009. Disponível em: < http://bvsms.saude.gov.br/bvs/publicacoes/direitos_sexuais_reprodutivos_metodos_anticoncepcionais.pdf $>$. Acesso em: 11 fev. 2016

CAMPOS, H. M.; ARAÚJO, I. C.; SCHALL, V. T. Oficinas em Sexualidade para Adolescentes: para eles por eles. Belo Horizonte: Centro de Pesquisas René Rachou/Fiocruz, 2011.

CAMPOS, H. M.; SCHALL, V. T.; NOGUEIRA, M. J. Saúde sexual e reprodutiva de adolescentes: interlocuções com a Pesquisa Nacional de Saúde do Escolar (PeNSE). Saúde em Debate, Rio de Janeiro, v. 37, n. 97, p. 336-346, 2013

CORRÊA, S.; ALVES, J. E. D.; JANUZZI, P. M. Direitos e saúde sexual e reprodutiva: marco teórico-conceitual e sistema de indicadores. In: CAVENAGHI, S. (Org.). Indicadores Municipais de saúde sexual e reprodutiva. Rio de Janeiro: Abep; Brasília, DF: UNFPA, 2006. p. 27-62.

FREIRE, P. A importância do ato de ler: em três artigos que se completam. 23. ed. São Paulo: Autores Associados: Cortez, 1989.

Pedagogia da autonomia: saberes necessários à prática educativa. 37. ed. São Paulo: Paz e Terra, 1996.
Pedagogia do oprimido. 17. ed. Rio de Janeiro: Paz e Terra, 1987.

HEILBORN, M. L. Por uma agenda positiva dos direitos sexuais da adolescência. Psicologia Clínica, Rio de Janeiro, v. 24, n. 1, p. 57-68, 2012.

Iniciação à Sexualidade: modos de socialização, interações de gênero e trajetórias individuais In: HEILBORN, M. L. et al. (Org.). O aprendizado da sexualidade: reprodução e trajetórias sociais de jovens brasileiros. Rio de Janeiro: Garamond; Fiocruz, 2006. p. 155-211.

\section{INSTITUTO BRASILEIRO DE GEOGRAFIA E} ESTATÍsTICA (IBGE). Pesquisa Nacional de Saúde do Escolar (PeNSE): 2015. Rio de Janeiro: IBGE, 2016.

MORAES, S. P.; VITALLE, M. S. S. Direitos Sexuais e reprodutivos na adolescência: interações ONU_ BRASIL. Ciência \& Saúde Coletiva, Rio de Janeiro, v. 20, n. 8, p. 2523-2531, 2015.

OZELLA, S.; AGUIAR, W. M. J. Desmistificando a Concepção de Adolescência. Cadernos de Pesquisa, São Paulo, v. 38, n. 133, p. 97-125, jan./abr. 2008.

\section{PAN AMERICAN HEALTH ORGANIZATION} (PAHO); WORLD HEALTH ORGANIZATION (WHO). Promotion of Sexual Health: Recommendations for Action. Guatemala: PAHO; WHO, 2000. Disponível em: <http://www.paho.org/english/hcp/hca/promotionsexualhealth.2000>. Acesso em: 13 fev. 2016.

PRESOT, I. M.; CAMPOS, H. M.; MODENA, C. M. Oficinas para profissionais de laboratórios de pesquisa biomédica. Revista Eletrônica Gestão \&t Saúde, Brasília, DF, v. 4, n. 4, p. 1300-1313, 2013.

RIOS, R. R. Por um direito democrático da sexualidade. Horizontes Antropológicos, Porto Alegre, v. 12, n. 26, p. 71-100, 2006.

RODRIGUES, L.; NOGUEIRA, C.; OLIVEIRA, J. M. Violência em casais LGB: estudo preliminar. In: 
NOGUEIRA, C.; OLIVEIRA, J. (Org.). Estudo sobre a discriminação em função da orientação sexual e da identidade de género. Lisboa: CIG, 2010. p. 243-266.

SANTOS, A. C. A lei do desejo: direitos humanos e minorias sexuais em Portugal. Porto: Afrontamento, 2005.

Entre duas mulheres isso não acontece: um estudo exploratório sobre violência conjugal lésbica. Revista Crítica de Ciências Sociais, Coimbra, n. 98, p. 3-24, 2012. Disponível em: <https://rccs.revues. org/4988>. Acesso em: 20 out. 2016.

SANTOS, B. S. Renovar a Teoria Crítica e Reinventar a Emancipação Social. São Paulo: Boitempo, 2007.

SCHALL, V. T. Educação em saúde no contexto brasileiro: influências sócio históricas e tendências atuais. Educação em Foco, Belo Horizonte, v. 1, n. 1, p. 41-48, 2005.
SEFFNER, F.; PARKER, R. Desperdício da experiência e precarização da vida: momento político contemporâneo da resposta brasileira à AIDS. Interface Comunicação, Saúde, Educação, Botucatu, SP, v. 20, n. 57, p. 293-304, 2016.

TEIXEIRA, A. M. F. B. et al. Adolescentes e uso de preservativos: as escolhas dos jovens de três capitais brasileiras na iniciação e na última relação sexual. Cadernos de Saúde Pública, Rio de Janeiro, v. 22, n. 7, p. 1385-1396, 2006.

Recebido para publicação em novembro de 2016

Versão final em abril de 2017

Conflito de interesses: inexistente

Suporte financeiro: não houve 